\title{
Geodiversidade e Geoconservação do estuário e manguezal rio Potengi: teoria e prática com alunos da Escola Municipal Terezinha Paulino
}

\author{
Geodiversity and Geoconservation of the Potengi river estuary and mangrove: theory and \\ practice with students of the Municipal School Terezinha Paulino
}

\author{
FERREIRA ${ }^{1}$, J. C. V.; MACIEL ${ }^{2}$, A. B. C.; $\operatorname{SILVA}^{3}$, C. C. L.; $\mathrm{LIMA}^{4}$, Z. M. C. \\ joyceclara@hotmail.com;
}

\begin{abstract}
Resumo
A educação ambiental serve como uma ferramenta de conscientização e de intervenção, através dela é possível compreender a complexidade dos sistemas ambientais aos quais se está inserido. Diante disso, o objetivo da pesquisa foi trabalhar a temática da Geodiversidade e Geoconservação do estuário e manguezal do rio Potengi junto aos alunos do $8^{\circ}$ ano da Escola Municipal Professora Terezinha Paulino de Lima durante a semana do meio ambiente. Além disso, buscou-se discutir os conceitos de Geodiversidade e Geoconservação, apresentar exemplos de geodiversidade e práticas da Geoconservação no Brasil, além de avaliar o entendimento dos alunos mediante às técnicas de ensino utilizadas. Os procedimentos metodológicos utilizados foram: o levantamento bibliográfico acerca da temática da Geodiversidade e da Geoconservação, elaboração de palestra e de duas oficinas voltadas para os alunos; e a realização de trabalho de campo destinado ao estuário e manguezal do rio Potengi, situado na cidade de Natal-RN. Diante disso, ao trabalhar com a temática da Geodiversidade e da Geoconservação de Natal, os alunos puderam conhecer seu município do ponto de vista ambiental e espacial, entender o conceito de Geosiversidade, atentar para importância de conservá-la e desenvolver trabalhos em equipe.
\end{abstract}

Palavras-chave: Geodiversidade; Geoconservação; Escola Municipal Professora Terezinha Paulino de Lima/Natal/RN.

\begin{abstract}
Environmental education serves as a tool for awareness and intervention, through which it is possible to see the complexity of the systems in question. In view of this, the objective of the research for the geodiversity and Geoconservation work of the estuary and mangrove of the Potengi river together with the students of the 8th year of the Municipal School Professor Terezinha Paulino de Lima during the environmental week. We sought to discuss concepts of geodiversity and Geoconservation, to present examples of geodiversity and practices of Geoconservation in Brazil, as well as to evaluate students' understanding through teaching techniques. The methodological procedures used for the bibliographic survey on geodiversity and Geoconservation, elaboration of lecture and two workshops aimed at students; And the accomplishment of field work to the market and mangrove of the Potengi river, located in the city of Natal-RN. Facing this, when working with a theme of geodiversity and Geoconservation of Natal, students can get to know their municipality from an environmental and spatial point of view, understand the concept of Geosiversity, pay attention to the importance of conserving and developing teamwork.
\end{abstract}

Keywords: Geodiversity; Geoconservation; Municipal School Terezinha Paulino /Natal/RN.

\footnotetext{
${ }^{1}$ Joyce Clara Vieira Ferreira, Doutoranda em Geografia/Laboratório de Geografia Física, Universidade Federal do Rio Grande do Norte, Natal-RN, Brasil.

${ }^{2}$ Ana Beatriz Câmara Maciel, Doutoranda em Geografia/Laboratório de Geografia Física, Universidade Federal do Rio Grande do Norte, Natal-RN, Brasil.

${ }^{3}$ Cleanto Carlos Lima da Silva, Departamento de Geografia/Laboratório de Geografia Física, Universidade Federal do Rio Grande do Norte, Natal-RN, Brasil.

${ }^{4}$ Zuleide Maria Carvalho Lima, Departamento de Geografia/Laboratório de Geografia Física, Universidade Federal do Rio Grande do Norte, Natal-RN, Brasil.
} 


\title{
1. INTRODUÇÃO
}

O estudo referente as questões ambientais se tornaram cada vez mais necessários, principalmente nos dias atuais, uma vez que se percebe com maior frequência a atuação do homem junto a natureza. Sabe-se que, por vezes, essa situação traz consigo inúmeras implicações tanto de cunho ambiental, econômico, social e cultural, visto que reflete diretamente nas condições de vida da população local tornando-as, assim, mais frágeis e vulneráveis aos efeitos das mudanças ambientais recorrentes.

Dessa maneira, entende-se que os ambientes atrativos para a atuação do homem, devem ser conhecidos do ponto de vista de sua dinâmica natural para o melhor desenvolvimento das diversas atividades, como bem ressalta Tricart (1979):

\begin{abstract}
Nuestro ambiente ecológico se modifica incesantemente. Está caracterizado por una dinámica que se manifiesta mediante unas interacciones entre diversos elementos. Para utilizar mejor este medio ambiente [...], sin destruirlo, para protegerlo contra las degradaciones que le harían incapazes de permitir la existência biológica del hombre, debemos conocer esta dinámica, y tener en cuenta estas interdependências. [...] La comprensión global de nuestro medio ambiente, necessária pra su utilización y para su protección, debe referirse fundamentalmente a su dinámica. (TRICART, 1979, p.15)
\end{abstract}

Contudo, as formas de atuação e exploração nas zonas costeiras, mais precisamente nas áreas estuarinas e nos manguezais são problemas evidentes na cidade de Natal, principalmente, por causar transformações severas no tocante as condições ambientais, paisagísticas e até mesmo culturais da população Natalense.

Nessa perspectiva, a educação ambiental serve como uma ferramenta de conscientização e de intervenção, e através dela é possível compreender a complexidade e dinamicidade dos sistemas ambientais aos quais se está inserido. Conforme Reigota (2009), os objetivos da educação ambiental consistem na conscientização, conhecimento, comportamento, competência, capacidade de avaliação e participação do indivíduo. Desse modo, pensando na educação ambiental e na semana do meio ambiente, instituída pelo Decreto $\mathrm{N}^{\mathrm{o}}$ 86.028, de 27 de maio de 1981, pensou-se na discussão das temáticas relacionada a Geodiversidade e Geoconservação do estuário e manguezais do rio Potengi, em conjunto com os alunos do $8^{\circ}$ ano da Escola Municipal Professora Terezinha Paulino de Lima localizada na cidade de Natal/RN.

O conceito de geodiversidade é considerado relativamente novo, uma vez que, surgiu na década de 1990. Desde então este conceito vem sendo ampliado por diversos autores, tais como: Eberhard (1997), Xavier da Silva e Carvalho Filho (2001), Veiga (1999), Stanley (2000), Nieto 
(2001), Gray (2004), Koslowski (2004), Brilha (2005), Araújo (2005), CPRM (2006), Cañadas e Flaño (2007) (Quadro 1).

Quadro 1: conceitos sobre geodiversidade encontrados na literatura conforme ordem cronológica. Fonte: Joyce Clara Vieira Ferreira (Set./2017).

\begin{tabular}{|c|c|c|}
\hline AUTORES & ANO & DEFINIÇÃO \\
\hline Eberhard & 1997 & $\begin{array}{l}\text { Corresponde a diversidade natural entre aspectos } \\
\text { geológicos, do relevo e dos solos. }\end{array}$ \\
\hline Veiga & 1999 & $\begin{array}{l}\text { define que a geodiversidade expressa as particularidades } \\
\text { do meio físico, compreendendo as rochas, o relevo, o } \\
\text { clima, os solos e as águas, subterrâneas e superficiais, e } \\
\text { condiciona a morfologia da paisagem e a diversidade } \\
\text { biológica e cultural. }\end{array}$ \\
\hline Stanley & 2000 & $\begin{array}{l}\text { Variedade de ambientes, fenômenos e processos } \\
\text { geológicos que produzem paisagens, rochas, minerais, } \\
\text { solos e outros depósitos superficiais formadores do } \\
\text { arcabouço que sustenta a vida na terra. }\end{array}$ \\
\hline Xavier da Silva e Carvalho Filho & 2001 & $\begin{array}{l}\text { definem geodiversidade a partir da variabilidade das } \\
\text { características ambientais de uma determinada área } \\
\text { geográfica. }\end{array}$ \\
\hline Nieto & 2001 & $\begin{array}{l}\text { O número e variedade de estruturas, formas e processos } \\
\text { geológicos que constituem o substrato de uma região, } \\
\text { sobre as quais está inserida a atividade biótica, incluindo a } \\
\text { antrópica. }\end{array}$ \\
\hline Gray & 2004 & $\begin{array}{l}\text { Variedade natural de feições ou elementos geológicos } \\
\text { (rochas, minerais e solos), geomorfológicos (formas de } \\
\text { relevo ou processos ativos) e de solo, incluindo suas } \\
\text { associações, relações, propriedades, interpretações e } \\
\text { sistemas. }\end{array}$ \\
\hline Koslowski & 2004 & $\begin{array}{l}\text { Variedade natural da superfície da Terra, em seus aspectos } \\
\text { geológicos, geomorfológicos, de solos e águas superficiais, } \\
\text { bem como outros sistemas resultantes de processos } \\
\text { naturais ou atividades humanas. }\end{array}$ \\
\hline Brilha & 2005 & $\begin{array}{l}\text { Compreende apenas aspectos não vivos do nosso planeta. } \\
\text { E não apenas os testemunhos provenientes de um passado } \\
\text { geológico (minerais, rochas, fósseis) mas também os } \\
\text { processos naturais que actualmente decorrem dando } \\
\text { origem a novos testemunhos. }\end{array}$ \\
\hline Araújo & 2005 & $\begin{array}{l}\text { Resultado dos processos interativos entre a paisagem, a } \\
\text { fauna, a flora e a forma como o homem se organiza. }\end{array}$ \\
\hline CPRM & 2006 & $\begin{array}{l}\text { Geodiversidade é a natureza abiótica (meio físico) } \\
\text { constituída por uma variedade de ambientes, fenômenos e } \\
\text { processos geológicos que dão origem às paisagens, rochas, } \\
\text { minerais, águas, solos, fósseis e outros depósitos } \\
\text { superficiais que propiciam o desenvolvimento da vida na } \\
\text { terra. (CPRM, 2006). }\end{array}$ \\
\hline Cañadas e Flaño & 2007 & $\begin{array}{l}\text { Variabilidade da natureza abiótica, os processos físicos da } \\
\text { superfície terrestre, os processos naturais e antrópicos que } \\
\text { compreendem a diversidade de partículas, elementos e } \\
\text { lugares. }\end{array}$ \\
\hline
\end{tabular}

Dentre os autores e conceitos citados, o presente trabalho pautou-se no conceito elaborado pela CPRM (2006) que trata a geodiversidade como a natureza abiótica formada por uma gama de 
ambientes, fenômenos e processos geológicos que originam as paisagens, rochas, minerais, águas, solos, fósseis, além de outros depósitos superficiais, capazes de propiciar o desenvolvimento das mais variadas formas de vida na Terra. Com base nisso, destacam-se também os valores atribuídos a geodiversidade, embasados em CPRM (2006) e Gray (2015), são eles: cultural, estético, econômico, científico, educativo e turístico.

A Geoconservação pode ser apreendida como sendo a fruição, uso consciente e proteção dos recursos da Geodiversidade (MANTESSO-NETO, 2010). Segundo Brilha (2005), a Geoconservação tem como objetivo a conservação e gestão do patrimônio geológico e processos naturais a ele associados.

Então, entende-se a Geoconservação como uma prática não isolada, no sentido de que requer uma participação da comunidade em conjunto com uma visão estratégica de gestão pública, pautada na multidisciplinaridade, apoiada em bases legais e que contemple etapas sequenciais, a fim de garantir a efetividade na conservação da Geodiversidade do estuário e do manguezal do rio Potengi localizado na cidade de Natal, estado do Rio Grande do Norte.

Assim, o presente artigo teve como objetivo principal trabalhar a temática da Geodiversidade e Geoconservação do estuário e manguezal do rio Potengi junto aos alunos do $8^{\circ}$ ano da Escola Municipal Professora Terezinha Paulino de Lima durante a semana do meio ambiente. Além disso, buscou-se discutir os conceitos de Geodiversidade e Geoconservação, apresentar exemplos de geodiversidade e práticas da Geoconservação no Brasil, além de avaliar o entendimento dos alunos mediante às técnicas de ensino utilizadas.

\section{METODOLOGIA}

De acordo com os objetivos proposto neste trabalho, procurou-se organizar os procedimentos metodológicos em conformidade com a necessidade de atendê-los, sendo apresentada a subdivisão das etapas em dois momentos: trabalhos de gabinetes e trabalhos empíricos. Nos trabalhos de gabinete foram realizados levantamentos bibliográficos e a preparação de seminários, enquanto que na etapa dos trabalhos empíricos realizou-se palestras, oficinas e aula de campo no estuário e manguezal do rio Potengi. (Figura 01). 


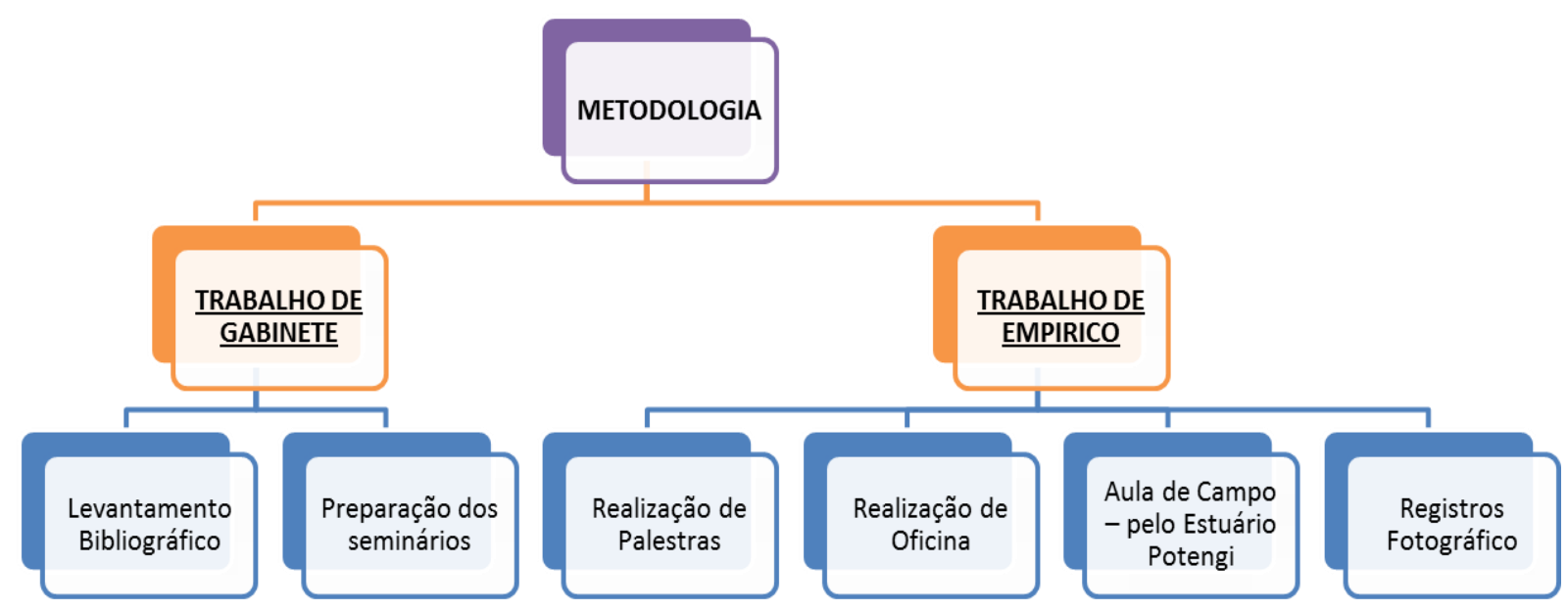

Figura 1: Organograma da Metodologia. Fonte: Ana Beatriz Câmara Maciel (Set./2017).

Para explanar acerca dos conceitos de geodiversidade e de geoconservação, foi realizada uma palestra sobre as temáticas, pautadas em conceitos e nos exemplos existentes no Brasil, fazendo uso de registros fotográficos e de referências bibliográficas nacionais e internacionais. A exposição da geodiversidade da cidade de Natal e as práticas da geoconservação do estuário e manguezal do rio Potengi, junto aos alunos da Escola Municipal Professora Terezinha Paulino de Lima, foram contempladas por meio de oficinas onde contou-se com a colaboração dos alunos do Programa de Pós-graduação e Pesquisa em Geografia da UFRN - PPGE/UFRN e prática de campo no rio Potengi em parceria com o projeto Barco Escola Chama Maré.

Os alunos assistiram a palestra intitulada "Geodiversidade e Geoconservação", para ampliarem os seus conhecimentos acerca da temática e também propor medidas para a geoconservação dos ambientes de estuário e manguezal. As oficinas foram implementadas utilizando um mapa de geofácies de Natal e uma matriz dos valores de geodiversidade, onde os alunos preencheram com base nos conhecimentos adquiridos. (Figura 01) 
A

\section{VALORES DA GEODIVERSIDADE DE NATAL-RN}

\begin{tabular}{|l|l|l|}
\hline EDUCATIVO & ECONÔMICO & CULTURAL \\
\hline & & \\
\hline & & \\
\hline & & \\
\hline & &
\end{tabular}

\begin{tabular}{|l|l|l|}
\hline & & \\
\hline & & \\
\hline & & \\
\hline
\end{tabular}

\begin{tabular}{|l|l|l|}
\hline & & \\
\hline & & \\
\hline & & \\
\hline & & \\
\hline & & \\
\hline & & \\
\hline & & \\
\hline & & \\
\hline
\end{tabular}

$\mathrm{B}$



Figura 2: A - matriz dos valores de geodiversidade de Natal a ser preenchida pelos alunos da Escola Municipal Professora Terezinha Paulino de Lima. B - Mapa de geofácies do município de Natal. Fonte: Joyce Clara Vieira Ferreira e Cleanto Carlos Lima da Silva.

O projeto Barco Escola Chama Maré foi criado pelo Governo do Estado do Rio Grande do Norte, em outubro de 2006, através do Instituto de Desenvolvimento Sustentável e Meio Ambiente - IDEMA (Órgão Ambiental do Estado RN), estando voltado para ações de educação ambiental e conservação do estuário do rio Potengi e do manguezal e, desde então, lança um olhar crítico para conservação destes ecossistemas presentes na cidade.

Durante a atividade de campo, foi percorrido um trecho do estuário do Potengi, partindo do Iate Clube de Natal, no sentido Fortaleza dos Reis Magos até a Boca da Barra. Durante o percurso passou-se sob a Ponte Newton Navarro, também denominada de Ponte Nova, retornando pela praia da Redinha Velha. Posteriormente, navegou-se em direção a Ponte de Igapó, também conhecida como Ponte Velha, que interliga a Zona Administrativa Norte a Zona Administrativa Leste. Por fim, retornou-se para o Iate Clube, passando pela Base Naval de Natal e pelo Porto de Natal.

Os alunos tiveram a oportunidade de vivenciar uma atividade ao ar livre pelo estuário, a bordo de um catamarã, com o intuito de se apoderarem de conhecimentos específicos sobre o 
estuário e o manguezal, onde foram observados diversos aspectos da paisagem: físicos, históricos, sociais e culturais, atentando para a importância de conservá-los.

A avaliação do entendimento dos alunos mediante as técnicas de ensino implementadas foi alcançada por meio dos diálogos acerca da temática durante as palestras, por meio das oficinas aplicadas na escola, através das discussões das respostas das matrizes aplicadas nos grupos de trabalho e por intermédio dos seminários realizados pelos alunos.

Por fim, para elaboração dos seminários, os alunos foram divididos em grupos para discutir o que aprenderam durante essa semana de atividade, em seguida foram organizadas as apresentações pautadas na Geodiversidade e Geoconservação da cidade de Natal. As temáticas discutidas foram: manguezal, estuário do rio Potengi, praias marinhas e patrimônio imaterial. Cada grupo de alunos apresentou um tema supracitado, expuseram as suas opiniões e citaram medidas de conservação para as áreas de estudo.

\section{RESULTADOS E DISCUSSÃO}

Para realização deste trabalho, foi necessária a subdivisão das atividades em quatro momentos, onde o primeiro momento, ocorrido no dia 07 de junho de 2017, pautou-se na introdução do tema Geodiversidade e Geoconservação para às turmas do $8^{\circ}$ ano "A" e "B" da Escola Municipal Professora Terezinha Paulino de Lima. Nessa etapa, contou-se com a colaboração da professora de geografia Ana Beatriz Câmara Maciel, que também subdividiu as turmas em grupos de trabalho (seis alunos por grupo).

Enquanto isso, no Departamento de Geografia da UFRN, foi idealizada uma matriz para o preenchimento de alguns valores da geodiversidade do rio Potengi e de seu manguezal (educativo, econômico e cultura) com base na CPRM (2006) e em Gray (2015), além da elaboração de um mapa das geofácies do município com base no banco de dados do Instituto de Desenvolvimento do Meio Ambiente (IDEMA). Também foram selecionadas fotografias da geodiversidade brasileira que auxiliaram na interação e compreensão dos alunos durante as palestras e da oficina.

O segundo momento foi consolidado no dia 08 de junho de 2017, onde foi realizada uma atividade de campo com destino ao estuário e manguezal do rio Potengi que, de acordo com Natal (2017), estão localizados entre: Zona de Proteção Ambiental 7 (ZPA-7), denominada de Forte dos Reis Magos e seu entorno e a Zona de Proteção Ambiental 8 (ZPA-8), denominada de Ecossistema manguezal e Estuário do Potengi/Jundiaí. Destaca-se que a ZPA-7 correspondem a um sítio de relevante valor artístico, arquitetônico, cultural, turístico e histórico, onde se encontra a Fortaleza dos Reis Magos. 

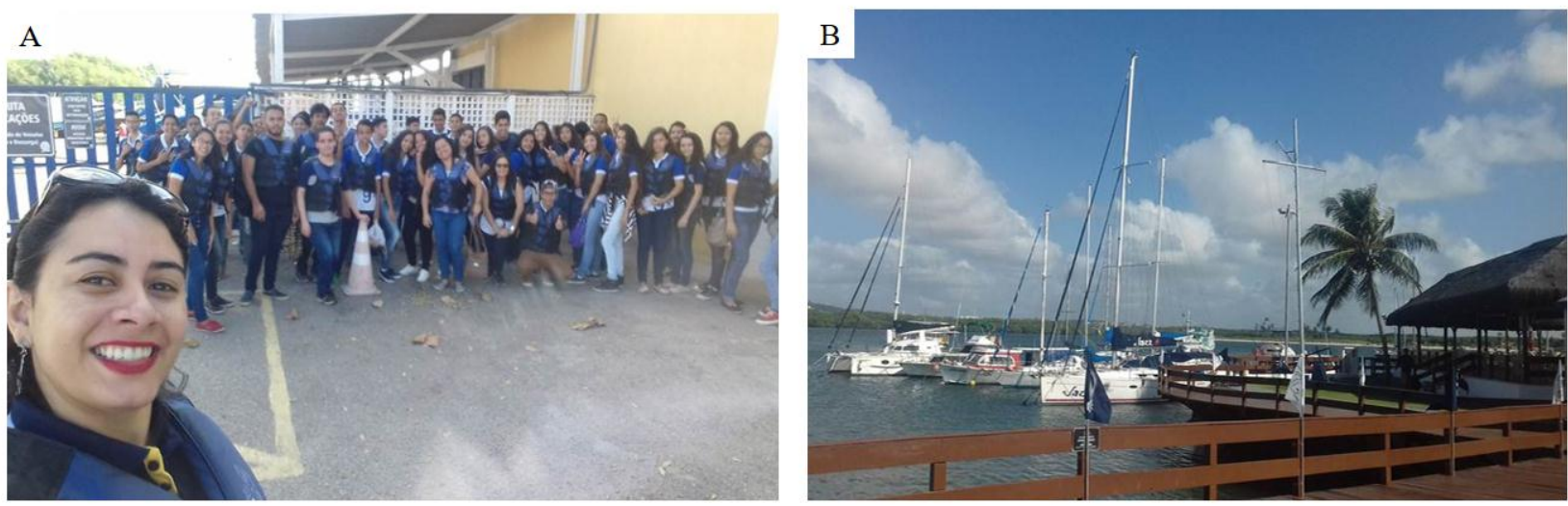

Figura 2: A - Preparação para aula de campo no Barco Escola Chama Maré junto aos alunos da Escola Municipal Professora Terezinha Paulino de Lima. B - Iate Clube de Natal-RN. Fotos: Ana Beatriz C. Maciel (Jun./2017).

A Fortaleza dos Reis Magos foi edificada na zona de praia, construída sob arrecifes adjacentes ao estuário do Potengi, sendo tombada pelo Patrimônio Histórico Nacional, conforme aborda Semurb (2010). A ZPA-8 abrange o ecossistema litorâneo de ampla importância ambiental e socioeconômica. Ressalta-se que é fonte de produção de alimentos, reprodução de espécies da fauna marinha, refúgio natural de peixes e crustáceos, meio propício à indústria pesqueira, atividades portuárias e recreativas, como, também, fonte de sustento para as populações ribeirinhas.

O terceiro momento deste trabalho consistiu em uma oficina realizada na Escola Municipal Professora Terezinha Paulino de Lima no dia 09 de junho de 2017, onde os alunos já embasados sobre o tema da Geodiversidade e Geoconservação, preencheram uma matriz com auxílio do mapa de Geofácies de Natal, objetivando identificar alguns valores da geodiversidade (educativos, econômicos e culturais) (Figura 4).
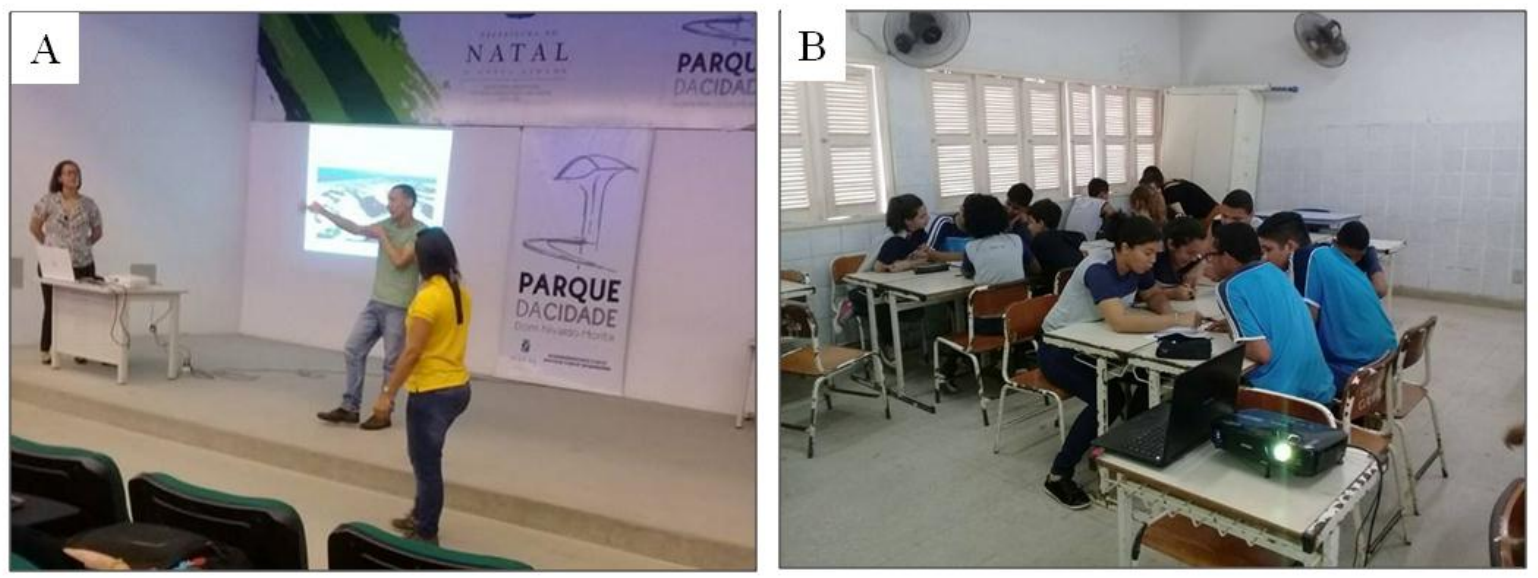

Figura 4: A) Palestra sobre Geodiversidade e Geoconservação proferida pelos alunos do PPGE/UFRN. B) Oficina realizada na Escola Municipal Professora Terezinha Paulino de Lima. Fotos: Ivaniza Sales (08 Jun./2017). 
Os resultados acerca dos trabalhos desenvolvidos com os alunos do $8^{\circ}$ ano da Escola Municipal Professora Terezinha Paulino de Lima atingiram os objetivos propostos. Ao trabalhar com as temáticas da Geodiversidade e da Geoconservação da cidade de Natal, os estudantes puderam conhecer seu município do ponto de vista ambiental e espacial, pois se observou que muitos não conseguem se localizar por meio de mapas.

Os alunos puderam perceber a importância de conservar a geodiversidade, uma vez que a mesma possui valores culturais, estéticos, econômicos, científicos, educativos e turísticos para sociedade; além de incitar o trabalho em equipe e o diálogo entre os componentes dos grupos. Os alunos apresentaram bom desempenho no tocante a atribuição de valores para as Geofácies mangue e corpos d'água continentais (rio Potengi) como pôde ser observado na Síntese das respostas dos alunos (Quadro 2).

Quadro 2: Síntese das respostas dos alunos da Escola Municipal Professora Terezinha Paulino de Lima referente aos valores de geodiversidade do município de Natal-RN. Fonte: Joyce Clara Vieira Ferreira (Set./2017).

\begin{tabular}{|c|c|c|c|}
\hline \multicolumn{4}{|c|}{ GEODIVERSIDADE DE NATAL-RN } \\
\hline \multirow{2}{*}{ GEOFÁCIES } & \multicolumn{3}{|c|}{ VALORES DA GEODIVERSIDADE } \\
\hline & EDUCATIVO & ECONÔMICO & CULTURAL \\
\hline Mangue & $\begin{array}{l}\text { - Estudo de espécies } \\
\text { - Estudo do ambiente }\end{array}$ & $\begin{array}{l}\text { - Coleta de } \\
\text { crustáceos } \\
\text { - Pesca }\end{array}$ & $\begin{array}{l}\text { - Carnaval da praia da } \\
\text { Redinha Velha (Bloco dos } \\
\text { Cão) } \\
\text { - Histórico da população } \\
\text { ribeirinha }\end{array}$ \\
\hline $\begin{array}{l}\text { Corpos d'água } \\
\text { continentais } \\
\text { (Rio Potengi) }\end{array}$ & $\begin{array}{l}\text { - Estudos sobre as } \\
\text { águas } \\
\text { - Projeto Barco Escola } \\
\text { Chama Maré }\end{array}$ & $\begin{array}{l}\text { - Turismo } \\
\text { - Pesca } \\
\text { - Comércio - Porto } \\
\text { de Natal }\end{array}$ & $\begin{array}{l}\text { - História do Rio Grande } \\
\text { do Norte (Ponte dos } \\
\text { Ingleses) } \\
\text { - Manifestações religiosas }\end{array}$ \\
\hline Praia marinha & $\begin{array}{l}\text { - Estudo de espécies } \\
\text { - Estudo do ambiente } \\
\text { - Estudo da qualidade } \\
\text { da água (Projeto Água } \\
\text { Viva) }\end{array}$ & $\begin{array}{l}\text {-Turismo } \\
\text {-Pesca } \\
\text {-Artesanato }\end{array}$ & $\begin{array}{l}\text { - Turismo } \\
\text { - Religiosidade (Estátua } \\
\text { de Iemanjá, cultos e } \\
\text { oferendas) } \\
\text { - Réveillon }\end{array}$ \\
\hline
\end{tabular}

Assim, após três dias de intensas atividades, pôde-se perceber que a maior parte dos alunos se mostrou participativa tanto no roteiro do Barco Escola Chama Maré quanto nas práticas realizadas na escola. Percebeu-se que os discentes entenderam o conceito e os valores da geodiversidade por meio das discussões em grupo e do preenchimento da matriz de valores de geodiversidade durante a 
oficina. A oficina mostrou-se uma ferramenta de grande importância, pois permitiu a aproximação entre os alunos e os palestrantes, além de possibilitar a integração de alunos com necessidades específicas no desenvolvimento dos exercícios propostos.

No quarto e último momento deste trabalho, foi idealizado um seminário temático, onde cada grupo de alunos ficou com um tema abordado durante a palestra, oficinas e atividade de campo. Os discentes se reuniram em grupo, na sala de aula para traçarem estratégias de elaboração e organização dos seminários. A proposta consistiu na preparação de uma apresentação em power point, contendo um mapa da cidade de Natal apresentando as feições estudadas, além das características físicas, sociais, econômicas e culturais da região, atreladas às medidas de Geoconservação que poderiam ser aplicadas em cada Geodiversidade, sendo esta capaz de dar suporte para biodiversidade (Figura 5).
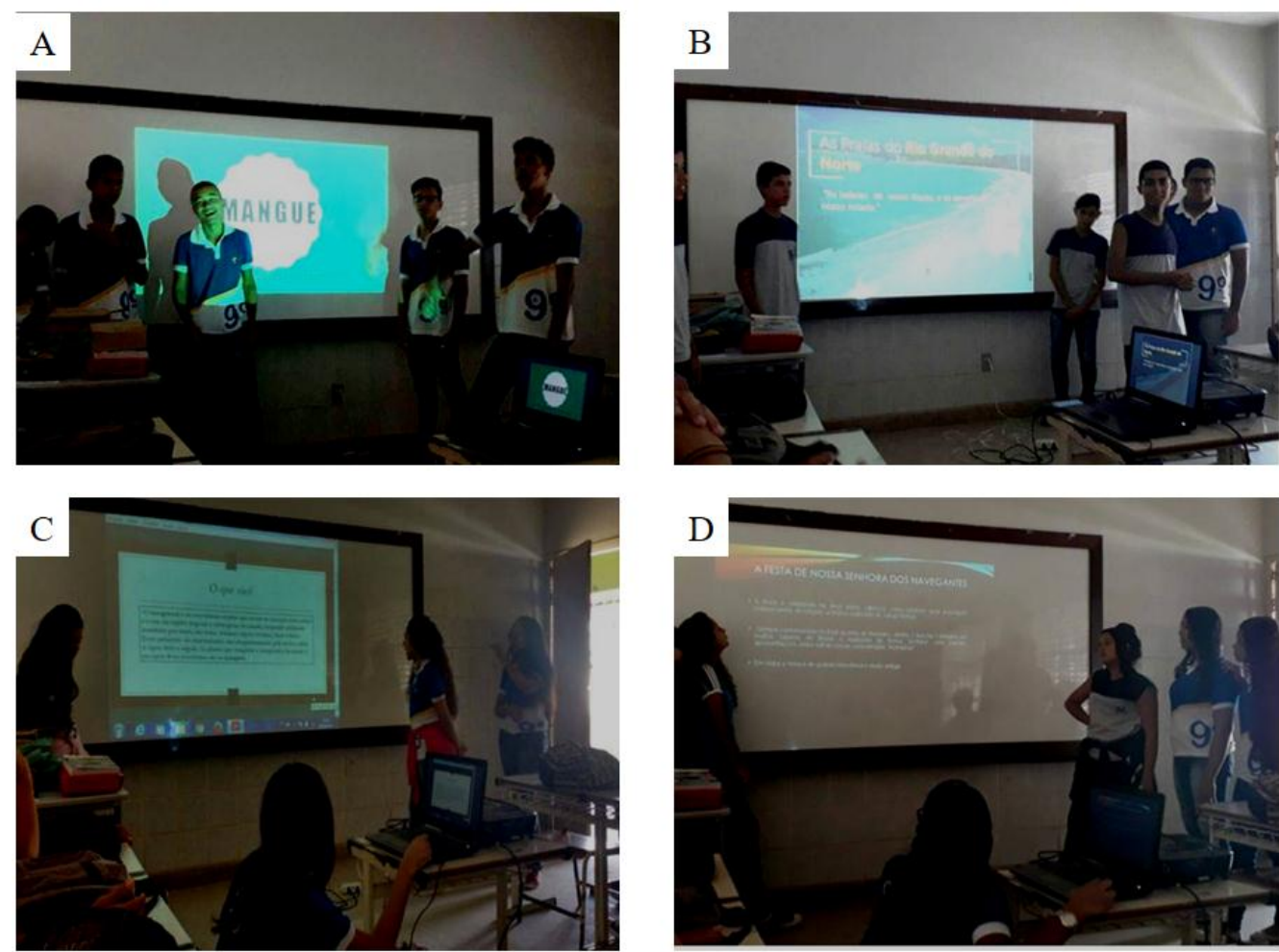

Figura 3: Apresentação dos grupos conforme as temáticas que foram abordadas durante o projeto.

Foto: Ana Beatriz C. Maciel (Junho/2017).

Após a exposição dos seminários temáticos pelos alunos, pode-se constatar que os mesmos conseguiram realizar várias pesquisas em sites e livros sobre as temáticas estudadas, e pode-se, também, avaliar a desenvoltura de cada aluno para mostrar a importância da Geodiversidade e da Geoconservação do estuário do Potengi e dos manguezais em Natal.

No tocante às ações de conservação ressalta-se que ao longo do século XX foram elaborados sucessivos instrumentos de proteção do patrimônio, estes foram implementados em 
escalas local, estadual, nacional e internacional. Os instrumentos associam o patrimônio geológico, geomorfológico ao patrimônio natural, porém, na prática existem poucos instrumentos legais específicos voltados para o patrimônio geológico. No Brasil uma das formas de proteção do patrimônio natural foi a promulgação da Lei n ${ }^{\circ} 9.985$ de 18 de julho de 2000 , que regulamenta o art. 225, $\S 1^{\circ}$, incisos I, II, III, e VII da Constituição Federal, onde foi instituído o Sistema Nacional de Unidades de Conservação da Natureza - SNUC, e estabelece critérios e normas para a criação, implantação e gestão das unidades de conservação.

Conforme aponta a lei $\mathrm{n}^{\mathrm{o}}$ 9.985, de 18 de julho de 2000, uma unidade de conservação pode ser considerada como um "espaço territorial e seus recursos ambientais, incluindo as águas jurisdicionais, com características naturais relevantes, legalmente instituído pelo Poder Público, com objetivos de conservação e limites definidos, sob regime especial de administração, ao qual se aplicam garantias adequadas de proteção" (SNUC, 2011, p. 5). Vale salientar que dentre os treze objetivos principais do SNUC, apenas um está diretamente relacionado ao patrimônio geológico (o sétimo objetivo), cuja finalidade é de "proteger as características relevantes de naturezas geológica, geomorfológica, espeleológica, arqueológica, paleontológica e cultural” (SNUC, 2011, p. 7).

\section{CONSIDERAÇÕES FINAIS}

Diante disso, conclui-se que os trabalhos desenvolvidos durante a Semana do Meio Ambiente com os alunos do $8^{\circ}$ ano (A e B) da Escola Municipal Professora Terezinha Paulino de Lima, Natal/RN foram considerados positivos, pois, ao trabalhar com as temáticas da Geodiversidades e da Geoconservação do município de Natal, os alunos puderam conhecer seu município do ponto de vista ambiental e espacial, entender o conceito de geodiversidade, e atentar para Geoconservação, além de desenvolver trabalhos em equipe em prol de um melhor resultado.

Portanto, acredita-se que por meio dessas práticas é possível conscientizar os alunos sobre a problemática ambiental e fazê-los refletir em como dirimir os impactos negativos que o homem vem deixando registrado na paisagem ao longo do tempo, com destaque para o estuário Potengi e para os manguezais da cidade de Natal. Assim, entende-se que através da educação ambiental pautada na conscientização, conhecimento sobre o tema, comportamento, capacidade de avaliação e participação é que se pode transformar o mundo e transmitir um legado positivo para as gerações futuras. 


\section{REFERÊNCIAS}

ARAÚJO, E.L.S. Geoturismo: conceitualização, implementação e exemplo de aplicação no Vale do Rio Douro no setor Porto Pinhão. Dissertação apresentada ao Programa de de Pósgraduação em Ciências do Ambiente. Escola de Ciências da Universidade do Minho, Portugal. 2005.

BRILHA, J. Patrimônio Geológico e Geoconservação: a conservação da natureza em sua vertente geológica. Braga: Palimage. 2005.

CAÑADAS, E. S. e Flaño, P.R. Geodiverdidad: concepto, evaluación e aplicácion territorial el caso de Tiermes Caracena (Soria). Boletín de la Asociación de Geógrafos Españoles, ISSN 02129426, No. 45, 2007.

CAÑADAS, E. S. e Flaño, P.R. Geodiverdidad: concepto, evaluación e aplicácion territorial el caso de Tiermes Caracena (Soria). Boletín de la Associación de Geógrafos Españoles, ISSN 02129426, No. 45, 2007.

EBERHARD, R. (Ed.). Pattern and process: towards a regional approach to national estate assessment of geodiversity. Technical Series, n. 2. Australian Heritage Commission; Environment Forest Taskforce, Environment Australia, Canberra, 1997.

GRAY, M. Geodiversity: valuing and conserving abiotic nature. Londres: John Willey \& Sons,. Chichester, 2004.

KOSLOWSKI, S. Geodiversity: the concept end scope of geodiversity. Przeglad Geologiczny, Vol. 52. 2004.

NATAL, Prefeitura Municipal do Natal. Parque da Cidade Dom Nivaldo Monte. Disponível em: http://natal.rn.gov.br/parquedacidade/ Acesso: 10/06/2017 às 15:00.

NIETO, L.M. Patrimônio Geológico Cultural y Turismo. Boletin del Instituto de Estudios Ginnenses. N ${ }^{\circ} 182,2001$.

REIGOTA, Marcos. O que é educação ambiental. 2. ed. Revista e ampliada: São Paulo: Brasiliense, 2009.

SNUC - Sistema Nacional de Unidades de Conservação da Natureza: Lei $\mathrm{n}^{\circ}$ 9.985, de 18 de julho de 2000; Decreto $n^{\circ} 4.340$, de 22 de agosto de 2002; Decreto ${ }^{\circ} 5.746$, de 5 de abril de 2006. Plano Estratégico Nacional de Áreas Protegidas: Decreto $n^{\circ}$ 5.758, de 13 de abril de 2006 / Ministério do Meio Ambiente. - Brasília: MMA/SBF, 2011.

STANLEY, M. Geodiversity. Earth Heritage, Vol. 18. 2000. 
TRICART, Jean; KILIAN, Jean. La eco-geografia y la ordenacion del medio natural. Barcelona: Editorial Anagrama, 1979.

VEIGA, A. T. C. A geodiversidade e o uso dos recursos minerais da Amazônia. Revista Terra das Águas, Brasília: NEAz/ UnB, n. 1, p. 88-102, 1999.

XAVIER DA SILVA, J.; CARVALHO FILHO, L. M. Índice de geodiversidade da restinga da Marambaia (RJ): um exemplo do geoprocessamento aplicado à geografia física. Revista de Geografia, Recife: DCG/UFPE, n. 1, p. 57-64, 2001.

\section{AGRADECIMENTOS}

Agradecemos a colaboração dos diretores, coordenadores e dos professores da Escola Municipal Professora Terezinha Paulino de Lima, localizada no Parque dos Coqueiros, na cidade de Natal/RN pelo auxilio na elaboração do projeto; agradecemos, também, a professora $\operatorname{Dr}^{\mathrm{a}}$. Zuleide Maria Carvalho Lima pela orientação; ao Programa de Pós-graduação e Pesquisa em Geografia da UFRN; e ao projeto Barco Escola Chama Maré pelo incentivo a divulgação e disseminação dos conhecimentos sobre a conservação e preservação do estuário e manguezal do rio Potengi, além de disponibilizar uma excelente logística no tocante ao desempenho das atividades (barco, marinheiros e monitores para a realização da aula de campo) buscando expandir conhecimento acerca das temáticas ambientais e culturais da cidade de Natal-RN.

Recebido em: 15/08/2018

Aceite para publicação em: 05/11/2018 